\title{
Determination of Organic Hydroperoxide Using Indamine Dye Formation Catalyzed by Water-Soluble Iron-Porphyrin and Its Reaction Mechanism
}

\author{
Taku Nakano, Mayumi Sakida, Satomi MiYata and Hirokazu Honda \\ Department of Pharmaceutical Sciences, Toyama Medical and Pharmaceutical University, \\ Sugitani, Toyama 930-01, Japan
}

\begin{abstract}
An assay method for determining organic hydroperoxides based on indamine dye formation using a water-soluble iron(III) porphyrin as catalyst was developed. The assay was performed at $\mathrm{pH} 4.4$ under anaerobic conditions and was applicable to flow-injection analysis. $t$-Butyl hydroperoxide was determined over the range of 1 to $40 \mathrm{nmol}$ with $r=0.999$ and $\operatorname{SD}(\%)=2.4(n=5$ at $4.8 \mathrm{nmol})$. The mechanism of the catalytic reaction is discussed based on kinetic measurements, suggesting a general acid-base catalyzed reaction involving a heterolytic cleavage of the $\mathrm{O}-\mathrm{O}$ bond.
\end{abstract}

Keywords Hydroperoxide, lipid peroxide, hemin, porphyrin, indamine dye, spectroscopic determination

The presence of activated oxygen and its derivatized species in biological systems has been focused on due to its medical importance. Unsaturated fatty acid peroxide (UFAPO) or lipid peroxide (LPO) is formed by radicals, such as hydroxy radical $(\cdot \mathrm{OH})$ or superoxide $\left(\mathrm{O}_{2}{ }^{-}\right)$, in biological systems. These peroxides affect the membrane and interfere with its functions; they are also suspected to be a potential cause of diseases ${ }^{1}$, and to have roles in the aging process. ${ }^{2}$

Because of the uncertainty in determining LPO or UFAPO ${ }^{3,4}$, the relation between various diseases and peroxides has not yet been clarified. An iodometric determination has traditionally been used in food and agricultural chemistries, and a small amount of peroxide has been detected using a thiobarbituric acid (TBA) method which was developed in clinical chemistry. ${ }^{5-7}$ However, it has been pointed out that the TBA method has a poor specificity to peroxide, and that the product formation was in the $10-20 \%$ range of the supposed amount. ${ }^{3,8}$ A method was recently introduced based on the formation of Methylene Blue by hydroperoxide catalyzed by hemoglobin. ${ }^{9}$ Other reported methods include an iodometric assay ${ }^{10}$, the formation of a Xylenol Orange-iron complex ${ }^{11}$, an assay using cyclooxygenase ${ }^{12}$ and HPLC methods. ${ }^{13}$ However, a more reliable assay method for peroxide is still necessary in order to overcome the uncertainty of the commonly used TBA method. ${ }^{8}$

We previously developed a method for the determination of hydrogen peroxide using a water-soluble iron (III) porphyrin (hemin, FeTMPyPCl 5$)^{14}$, which is now being applied to organic hydroperoxide with a slight modification. An indamine dye formation system using horse radish peroxidase (HRP) had been proposed for detecting hydrogen peroxide. ${ }^{15-18}$ Our previous system $^{14}$ was used to specifically determine hydrogen peroxide using water-soluble porphyrin as a catalyst instead of HRP in an acidic media (pH 1 -2). It was noted that when it was applied at low $\mathrm{pH}(1-2)$ only hydrogen peroxide reacted to form a dye; on the other hand, molecular oxygen and organic hydroperoxide developed color in a higher $\mathrm{pH}$ region $(3-6)$.

In this report we describe our adoption of this reaction for determining organic hydroperoxide, $t$-butyl hydroperoxide $(t-\mathrm{BuOOH})$ and cumene hydroperoxide $(\mathrm{CuOOH})($ Fig. 1). The reaction was performed in the $3-5 \mathrm{pH}$ region and had to be carried out under anaerobic conditions in order to avoid oxidation by molecular oxygen.

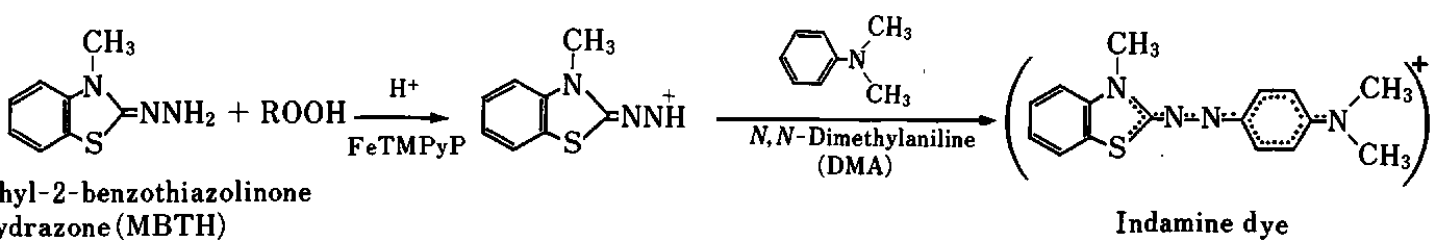

Fig. 1 Coupling reaction forming indamine dye. 
The study of the reaction mechanism was intended to. confirm the stoichiometry of the reaction, which would assure the reproducibility of the reaction. Another purpose was to answer questions concerning the reaction mechanism. For instance, it was known that alkyl hydroperoxide reacted with oxyhemoglobin to form the alkoxy radical, which initiated additional reactions. ${ }^{19}$ In studying model-hemin systems, two mechanisms were proposed regarding cleavage of the $\mathrm{O}-\mathrm{O}$ bond of hydroperoxide on hemin, namely heterolytic or homolytic. In the former case, the reaction involves an ionic process; in the latter case the reaction is a radical process. If the mechanism is heterolytic, the reaction stoichiometry would hold; and if it is homolytic, the alkoxy radical could be produced and then followed by a chain reaction.

\section{Experimental}

\section{Materials and reagent solutions}

Freshly distilled $N, N$-dimethylaniline (DMA)(Wako Pure Chemical Ind.) was dissolved in $0.1 \mathrm{~mol} \mathrm{dm}^{-3}$ hydrochloric acid to be $2.06 \times 10^{-2} \mathrm{~mol} \mathrm{dm}^{-3}$ (Solution A).

3-Methyl-2-benzothiazolinone hydrazone hydrochloride (MBTH) (Wako Pure Chemical Ind.) was dissolved in deionized water to be $4.28 \times 10^{-3} \mathrm{~mol} \mathrm{dm}^{-3}$ (Solution B).

meso-Tetrakis(1-methyl-4-pyridyl)porphinatoiron(III) pentachloride $\left(\mathrm{FeTMPyPCl}_{5}\right)$ was made by inserting iron into meso-tetrakis (1-methyl-4-pyridyl)porphyrin $\left(\mathrm{H}_{2} \mathrm{TMPyP}\right)($ Dojindo Lab.). Iron insertion was performed following a method described in the literature ${ }^{20}$, except for using $N, N$-dimethyl acetamide instead of $N, N$-dimethyl formamide as the solvent; it resulted in an easy separation of excess iron in the form of precipitated iron oxide. $\mathrm{FeTMPyPCl}_{5}$ was purified by repeated recrystallization from hydrochloric acid $\left(6 \mathrm{~mol} \mathrm{dm}^{-3}\right)$ while being evaporated at room temperature. The formed precipitate was dried in a desiccator over sodium hydroxide. $\mathrm{FeTMPyPCl}_{5}$ was dissolved in deionized water and the concentration was adjusted to be $1.0 \times 10^{-4} \mathrm{~mol} \mathrm{dm}^{-3}$ (Solution F).

$t$-Butyl hydroperoxide $(t$-BuOOH)(Aldrich) and cumene hydroperoxide ( $\mathrm{CuOOH}$ )(Aldrich) were assayed iodometrically according to a method described in the literature. ${ }^{21}$ An appropriate amount of hydroperoxide was dissolved in isopropyl alcohol containing $20 \%$ sodium iodide in a flask with a condenser; the mixture was then refluxed in a water bath for $10 \mathrm{~min}$. After cooling in an ice-cold water bath, the liberated iodine was titrated by sodium thiosulfate. Hydroperoxide was diluted in a buffer solution (Solution $\mathrm{H}$ ).

Phthalate buffer $\left(0.05 \mathrm{~mol} \mathrm{dm}^{-3}\right)$ was used for the determination and kinetic measurements and phosphate buffer $\left(0.05 \mathrm{~mol} \mathrm{dm}^{-3}\right)$ was also used for checking any $\mathrm{pH}$ effect on the reaction. Nitrogen gas was passed through Oxisorb (Messer Grieshem) in order to eliminate contaminated oxygen.

All of the other chemicals used were of reagent grade.

\section{Apparatus}

A Hitachi-220A spectrophotometer was used with an attached water circulator. Long-necked cuvettes with silicone rubber stoppers were used under anaerobic conditions. Bio-Rad Model EP-1 pumps and a Hitachi LC flow system attached to the spectrometer were used for a flow-injection analysis system (FIA). The pHs were checked with a Horiba H-7 LD pH meter.

\section{General procedure}

Into a glass cuvette of $1 \mathrm{~cm}$ length and a long neck with a silicon rubber stopper, $0.2 \mathrm{ml}$ of Solution A (DMA), $0.2 \mathrm{ml}$ of Solution B (MBTH), $0.5 \mathrm{ml}$ of Solution F (FeTMPyPCl ) and $2.0 \mathrm{ml}$ of the buffer solution ( $\mathrm{pH} \mathrm{4.4)}$ were charged; the mixed solution was then degassed by passing nitrogen gas through it. To the mixed solution $0.3 \mathrm{ml}$ of degassed Solution $\mathrm{H}(t-\mathrm{BuOOH}, \mathrm{CuOOH})$ was injected, and the solution was shaken; the absorbance at $590 \mathrm{~nm}$ was measured after $30 \mathrm{~min}$.

For the flow-injection system shown in Fig. 2, degassed mixed solutions of $A$ and $F$ and Solution $B$ were mixed and $30-100 \mu \mathrm{l}$ sample solutions of $H$ were injected into the flow. The reaction coil was kept at $30^{\circ} \mathrm{C}$. The absorbance was monitored by a detector at $590 \mathrm{~nm}$ after $6 \mathrm{~min}$; within that period $80-90 \%$ of the production was reached with good reproducibility.

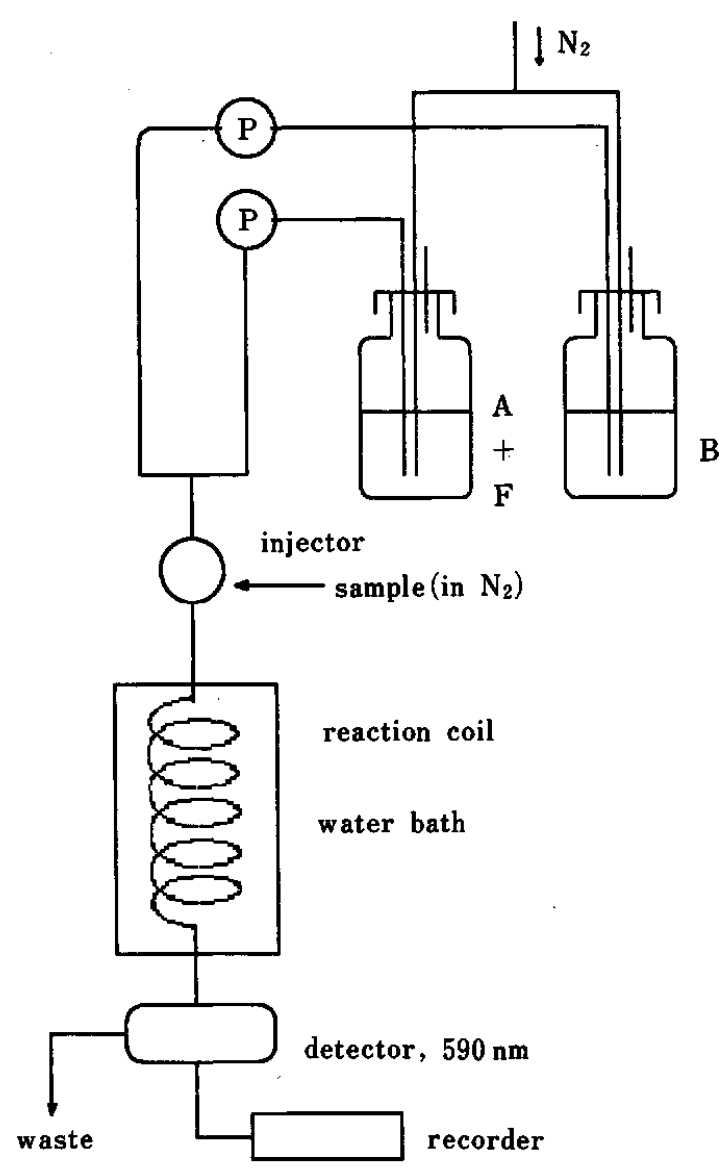

Fig. 2 Flow system used in measuring organic hydroperoxide. 


\section{Kinetic measurements}

Into a cuvette $(1 \mathrm{~cm}$ in length with a long neck and a silicon rubber stopper) containing an MBTH solution, and buffered solutions ( $\mathrm{pH} \mathrm{4.4)}$ of DMA and FeTM$\mathrm{PyPCl}_{5}, 10-100 \mu \mathrm{l}$ of the degassed $t$-BuOOH solution was injected to start the reaction. The reaction conditions are indicated in the figure captions. The reaction rates were determined by following the increase in the absorbance at $590 \mathrm{~nm}$.

\section{Results and Discussion}

\section{Formation of indamine dye}

In this system indamine dye was formed by the oxidative coupling between MBTH and DMA (Fig. 1). The reaction was initially developed for the determination of aromatic amines and imino heteroaromatic compounds $^{22}$, and was then applied later for the determination of hydrogen peroxide using peroxidase as a catalyst and the activity of peroxidase itself. ${ }^{15-18}$

Our previous method ${ }^{14}$ using synthetic hemin, FeTM$\mathrm{PyPCl}_{5}$, has been expanded for the determination of organic hydroperoxide using water-soluble iron(III) porphyrin; it was shown to be a useful method for determining lipid peroxide. In the $3-5 \mathrm{pH}$ region any examined ordinary enzymes would be less active, and would not influence the determination. The resulting color of the dye was stable and its visible spectrum was the same as in the case of hydrogen peroxide. ${ }^{14}$ In a preliminary experiment, the molecular extinction coefficient of indamine dye was determined to be $3.87 \times 10^{4}$.

The $\mathrm{pH}$ dependency of the reaction was checked by following the time course of the color formation, as

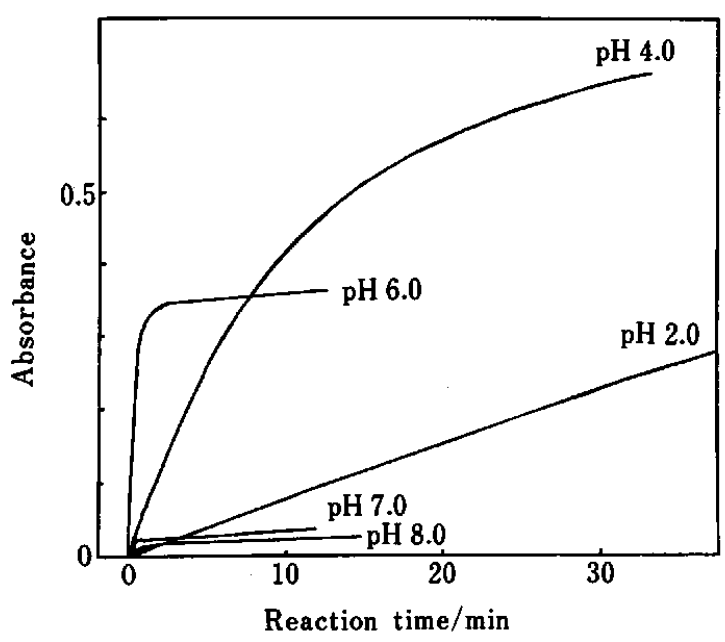

Fig. 3 Time course of the color formation with $t$-BuOOH at various $\mathrm{pH}\left(25^{\circ} \mathrm{C}\right)$. The final concentrations of the reagents were $1.45 \times 10^{-5} \mathrm{~mol} \mathrm{dm}^{-3}$ for $\mathrm{FeTMPyPCl}_{5}, 1.24 \times 10^{-3}$ mol dm${ }^{-3}$ for MBTH, $5.97 \times 10^{-3} \mathrm{~mol} \mathrm{dm}^{-3}$ for DMA and $2.89 \times 10^{-5} \mathrm{~mol} \mathrm{dm}^{-3}$ for $t$-BuOOH. The concentration of phthalate buffer was $7.4 \times 10^{-2} \mathrm{~mol} \mathrm{dm}^{-3}$. shown in Fig. 3. When examined in detail, it was clearly observed that the rate of the reaction increased at higher pH until 4-5, but slowed beyond $\mathrm{pH} \mathrm{5-6.} \mathrm{At} \mathrm{pH} \mathrm{6-8,}$ the reaction quickly stopped after the initial immediate increase. A similar phenomenon had been observed in the case of hydrogen peroxide ${ }^{14}$, and the reduction of hemin was observed in both cases of hydroperoxide and hydrogen peroxide at $\mathrm{pH}$ 6-8. From a detailed examination using a phthalate buffer the optimum $\mathrm{pH}$ for the assay was determined to be 4.4. As molecular oxygen reacted to increase dye formation at the $\mathrm{pH}$ studied ${ }^{14}$, solution degassing was necessary by passing nitrogen gas. Due to a spontaneous formation of dye at pH 4.4, a blank test was required.

The reaction was checked at $10,20,30$ and $40^{\circ} \mathrm{C}$. Although the rate increased at higher temperatures, a slight decomposition of hemin occurred at $40^{\circ} \mathrm{C}$. The experiments described below were performed at room temperature $\left(25^{\circ} \mathrm{C}\right)$ and $30^{\circ} \mathrm{C}$ for FIA.

\section{Reproducibility and calibration curve}

Similarly, as described in a previous paper ${ }^{14}$, the spectra taken after the reaction indicated that the catalyst hemin remained unchanged in the $1-5 \mathrm{pH}$ region, clarifying the reproducibility of the reaction. A plot of the absorbance against the concentration of $t$-BuOOH and $\mathrm{CuOOH}$ in Fig. 4 shows a bending, which suggests that at higher concentrations the hydroperoxide, itself, reacted as a substrate, as had been described in the literature. ${ }^{23-30}$ On the other hand, the linearity was observed at low concentrations using the FIA method. Over the $1-40 \mathrm{nmol}$ range of injection a linearity of the calibration curve was obtained by using $t-\mathrm{BuOOH}$, as

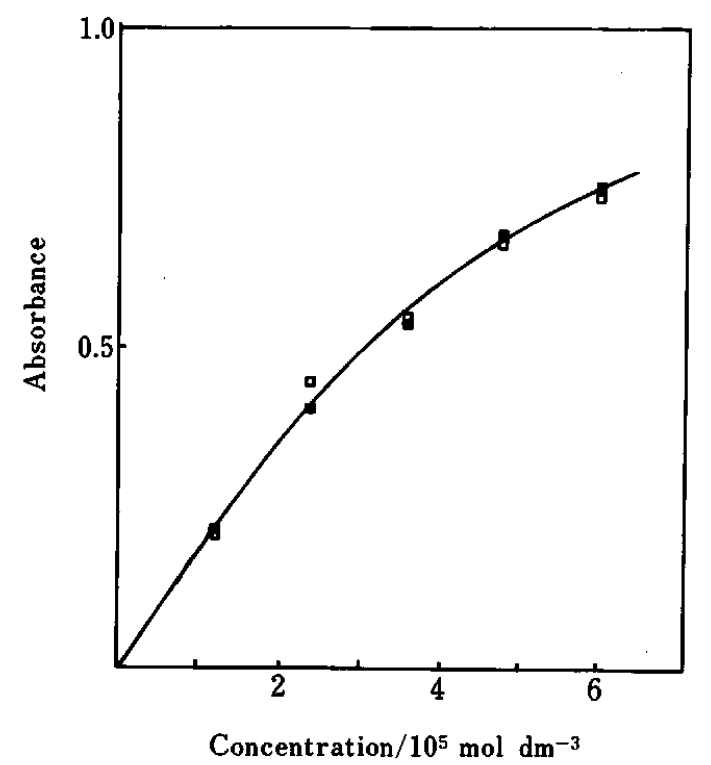

Fig. 4 Plot of $t$-BuOOH and $\mathrm{CuOOH}\left(25^{\circ} \mathrm{C}\right)$. The final concentrations of the reagents were $1.18 \times 10^{-5} \mathrm{~mol} \mathrm{dm}^{-3}$ for FeTMPyPCl $5,2.0 \times 10^{-3} \mathrm{~mol} \mathrm{dm}^{-3}$ for MBTH and $4.9 \times 10^{-3}$ mol dm $\mathrm{m}^{-3}$ for DMA. The concentration of phthalate buffer was $3.8 \times 10^{-2} \mathrm{~mol} \mathrm{dm}^{-3}$. 
shown in part in Fig. 5. The correlation factor was 0.999 and $\mathrm{SD}(\%)$ was $2.4(n=5)$ when $4.8 \mathrm{nmol}$ was injected. As for $\mathrm{CuOOH}$, the observed linear relation showed $r=0.998$.

\section{Effect of foreign materials on the determination}

The effect of materials which were supposed to be present in samples was examined in the FIA system, the results of which are given in Table 1. No severe interference was observed, except for the following. The presence of such reducing reagents as ascorbic acid, glutathione or iron(II) sulfate reduced the hydroperoxide competing with dye formation. Iron(III) and copper(II) ions which caused a positive effect on the formation of dye could be masked by adding EDTA (ethylenediaminetetraacetic acid), as indicated in Table 1. In case of $\mathrm{FeCl}_{3}$, the addition of EDTA of about $10^{-3}$ mol dm ${ }^{-3}$ was enough, but in the $\mathrm{CuCl}_{2}$ case $10^{-2} \mathrm{~mol}$ $\mathrm{dm}^{-3}$ of EDTA was necessary. There were some cases in which spontaneous dye formation occurred without any oxidant or catalyst, though its cause was not clear at this stage. The addition of EDTA or citric acid was found to be effective for reducing the spontaneous formation of dye.

Kinetic measurements and the rate equation with $t-\mathrm{BuOOH}$

Generally, in biological systems oxygen is thought to convert to become a radical species that reacts rather rapidly with biological materials. To clarify the

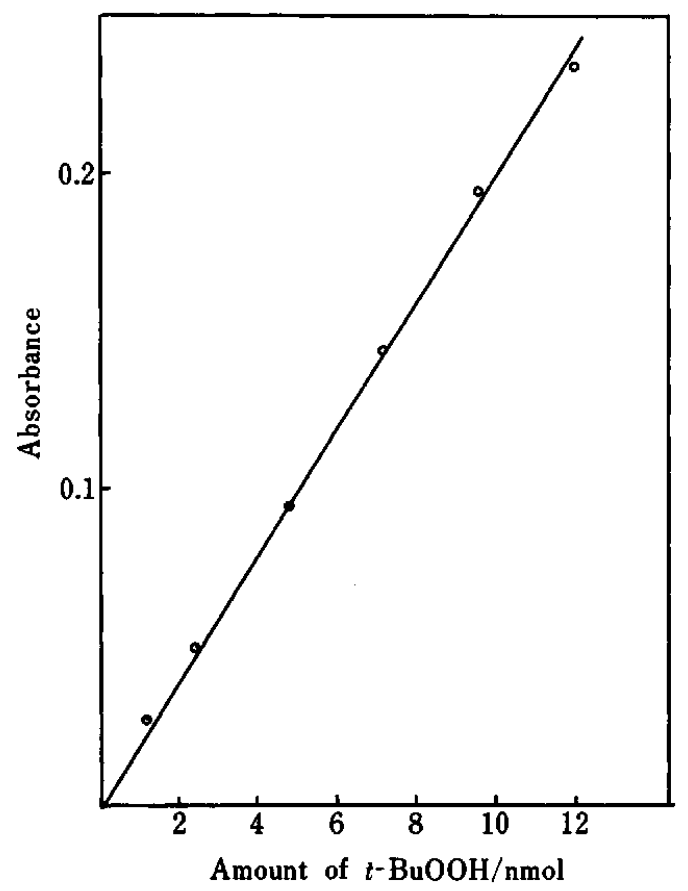

Fig. 5 Calibration curve with $t$-BuOOH in FIA $\left(30^{\circ} \mathrm{C}\right)$. Thirty microliters of a $t$-BuOOH solution was injected. The flow rate was $0.3 \mathrm{ml} \mathrm{min}{ }^{-1}$. The concentrations of the reagents in the flow were $1.7 \times 10^{-5} \mathrm{~mol} \mathrm{dm}^{-3}$ for $\mathrm{FeTMPyPCl}_{5}, 1.7 \times 10^{-3} \mathrm{~mol} \mathrm{dm}^{-3}$ for MBTH, $7.0 \times 10^{-3} \mathrm{~mol}$ $\mathrm{dm}^{-3}$ for DMA. The concentration of phthalate buffer was $2.8 \times 10^{-2} \mathrm{~mol} \mathrm{dm}^{-3}$.

Table 1 Effect of foreign materials ${ }^{\mathrm{a}}$

\begin{tabular}{|c|c|c|c|}
\hline Compound & $\begin{array}{c}\text { Difference }^{\mathbf{b}} \text {, } \\
\%\end{array}$ & Compound & $\begin{array}{c}\text { Difference }^{\mathrm{b}}, \\
\%\end{array}$ \\
\hline $\mathrm{NH}_{4} \mathrm{Cl}$ & +0.25 & EDTA & $-19.3^{f}$ \\
\hline $\mathrm{KCN}$ & +6.61 & Glycine & -1.53 \\
\hline KI & +4.70 & L-Proline & 0.0 \\
\hline $\mathrm{NaN}_{3}$ & -5.94 & L-Phenylalanine & +2.30 \\
\hline $\mathrm{NaBr}$ & +0.25 & Imidazole & +2.53 \\
\hline $\mathrm{CaCl}_{2}$ & -1.06 & Bilirubin & $-0.48^{\mathrm{g}}$ \\
\hline $\mathrm{NiCl}_{2}$ & +1.05 & Trichloroacetic acid & +4.92 \\
\hline $\mathrm{MgSO}_{4}$ & -7.42 & $1 \%$ & +11.7 \\
\hline $\mathrm{Zn}\left(\mathrm{CH}_{3} \mathrm{COO}\right)_{2}$ & +3.47 & $3 \%$ & +9.84 \\
\hline $\mathrm{Co}\left(\mathrm{NO}_{3}\right)_{2}$ & +2.30 & Levelose & +4.04 \\
\hline $\mathrm{FeSO}_{4}$ & -91.8 & L- $\alpha$-Alanine & +2.53 \\
\hline $\mathrm{CuCl}_{2}$ & $-^{c}$ & Acetic acid & +5.57 \\
\hline$+\operatorname{EDTA}\left(10^{-2}\right)$ & -12.2 & Ascorbic acid & $-^{\mathrm{h}}$ \\
\hline$+\operatorname{EDTA}\left(10^{-3}\right)$ & +106 & Pottasium citrate & -23.8 \\
\hline$+\operatorname{EDTA}\left(10^{-4}\right)$ & +168 & Urea & +4.56 \\
\hline $\mathrm{FeCl}_{3}$ & $+34.1^{\mathrm{c}}$ & Glucose & $+3.80^{d}$ \\
\hline$+\operatorname{EDTA}\left(10^{-2}\right)$ & -11.5 & & $+6.07^{\mathrm{e}}$ \\
\hline$+\operatorname{EDTA}\left(10^{-3}\right)$ & -16.9 & Gluthathione & $\ldots h, i$ \\
\hline$+\operatorname{EDTA}\left(10^{-4}\right)$ & +13.6 & Albumin, human & $-1.77^{\mathrm{j}}$ \\
\hline
\end{tabular}

a. Concentrations of $t$-BuOOH and foreign materials were $2.4 \times 10^{-4}$ and $2.4 \times 10^{-3} \mathrm{~mol} \mathrm{dm}^{-3}$ respectively, unless otherwise noted $(100 \mu \mathrm{l}$ injected). b. Differences in percentage were those between numbers with and without foreign materials. c. Fe(III) and $\mathrm{Cu}$ (II) ions reacted without hydroperoxide. d. $1.8 \times 10^{-2} \mathrm{~mol} \mathrm{dm}^{-3}$. e. $1.8 \times 10^{-3} \mathrm{~mol} \mathrm{dm}^{-3}$. f. $1.0 \times 10^{-2} \mathrm{~mol} \mathrm{dm}^{-3}$. g. $0.5 \mathrm{mg}$ $\mathrm{dl}^{-1}$. h. Ascorbic acid and glutathione reduced hydroperoxide quickly. i. $50 \mathrm{mg} \mathrm{dl}^{-1}$. j. Because of the low solubility of albumin the supernatant was added. 
mechanism for the formation of activated species or an intermediate is important since, if during the reaction hydroxy or alkoxy radicals are formed, it would react quickly to cause other reactions. If these radicals are not formed, the stoichiometry of the reaction (Fig. 1) holds in this case. A kinetical study would answer this question.

Typical kinetic results with $t$-BuOOH are shown in Fig. 6. The reaction was revealed to be pseudo-first order when the reaction was plotted as $\log \left(A_{\infty}-A_{t}\right)$ against time. The initial rates were obtained from the time courses of the reactions. Figures 7, 8 and 9 show linear relations between the initial rates at $\mathrm{pH} 4.4$ and the concentrations of the reactants and the catalyst, $t$ $\mathrm{BuOOH}, \mathrm{DMA}$ and $\mathrm{FeTMPyPCl}$, respectively. On

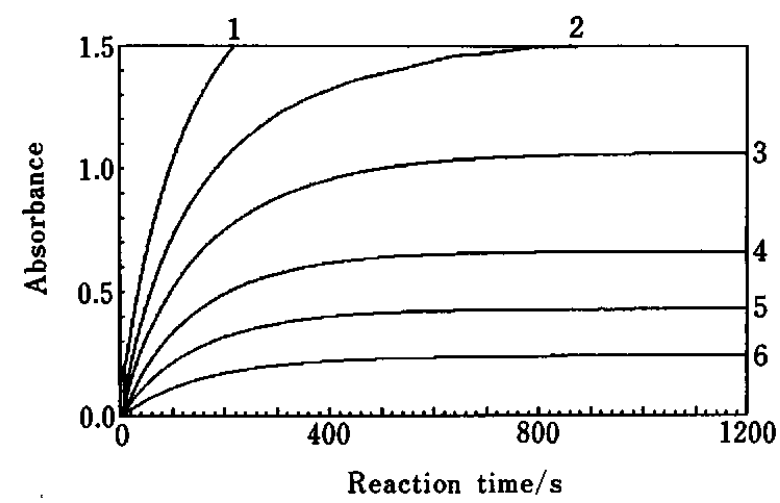

Fig. 6 Time course of the reaction at various amounts of $t$-BuOOH $\left(25^{\circ} \mathrm{C}\right)$. Concentration of reagents: $1.45 \times 10^{-5}$ mol dm ${ }^{-3}$ for FeTMPyPCl, $5.97 \times 10^{-3} \mathrm{~mol} \mathrm{dm}^{-3}$ for DMA and $1.24 \times 10^{-3} \mathrm{~mol} \mathrm{dm}^{-3}$ for MBTH. Concentration of $t$ BuOOH $\left(\times 10^{-5} \mathrm{~mol} \mathrm{dm}^{-3}\right)$; 1: 11.6, 2: 5.78, 3: 2.89, 4: 1.45, 5: $0.72,6: 0.29$. Concentration of phthalate buffer was $2.1 \times 10^{-2} \mathrm{~mol} \mathrm{dm}^{-3}$.

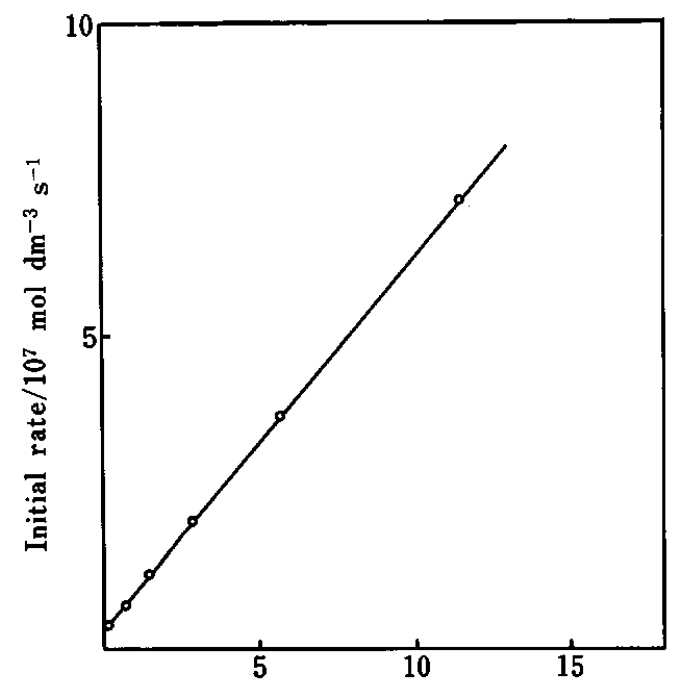

Concentration of $t-\mathrm{BuOOH} / 10^{5} \mathrm{~mol} \mathrm{dm}{ }^{-3}$

Fig. 7 Kinetic plot of the reaction for $t-\mathrm{BuOOH}\left(25^{\circ} \mathrm{C}\right)$. The concentrations of the reagents were the same as in Fig. 6 . the other hand, the initial reaction rate was revealed to be independent of the concentration of MBTH. The intercepts at zero concentration indicated the "spontaneous" reaction rates.

The kinetic results thus showed that the catalyzed reaction was third order regarding with the concentrations of FeTMPyPCl 5 , DMA and $t-\mathrm{BuOOH}$, and that the rate equation (Eq. (1)) for the initial stage of the reaction can be written

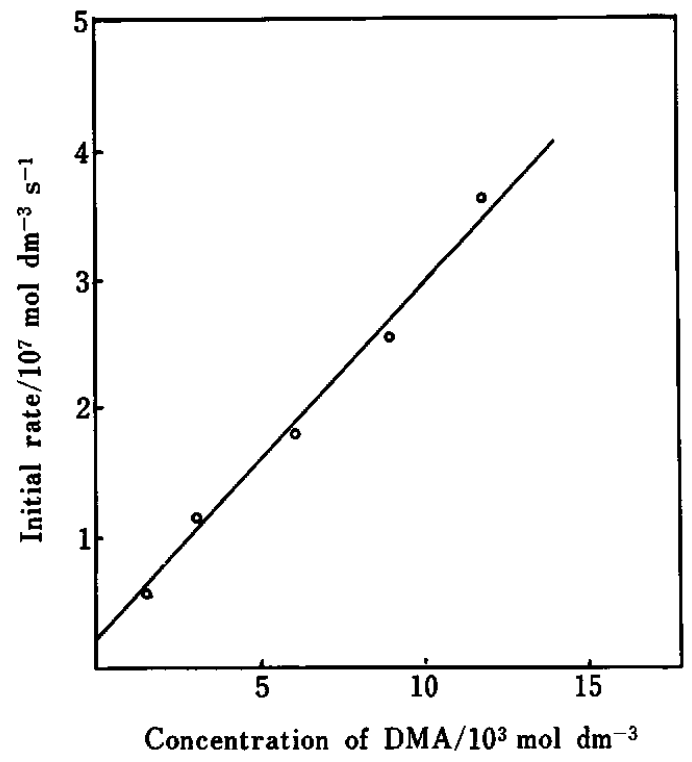

Fig. 8 Kinetic plot of the reaction for DMA $\left(25^{\circ} \mathrm{C}\right)$. The concentrations of the reagents were the same as in Fig. 6 except for DMA and $[t-\mathrm{BuOOH}]=2.89 \times 10^{-5} \mathrm{~mol} \mathrm{dm}^{-3}$.

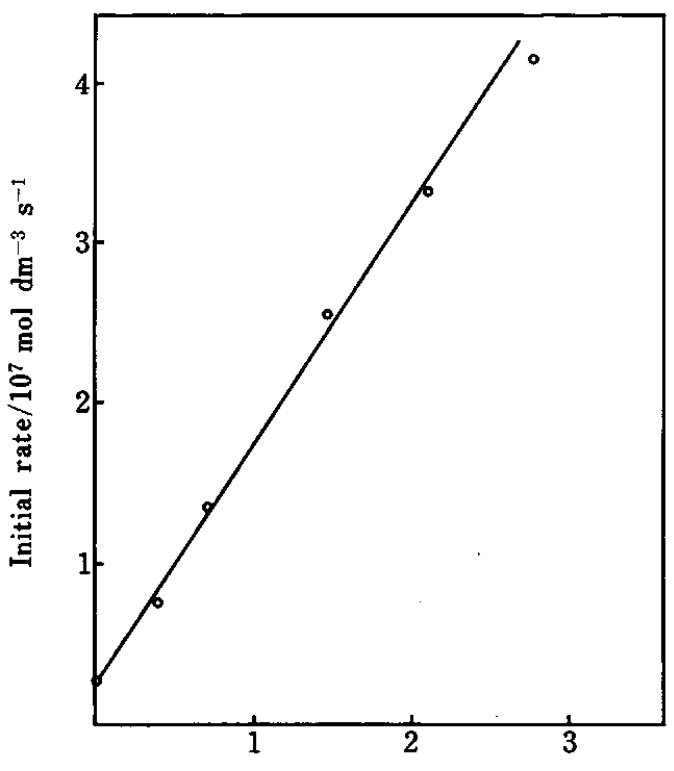

Concentration of $\mathrm{FeTMPyPCl} / 5 / 10^{5} \mathrm{~mol} \mathrm{dm}^{-3}$

Fig. 9 Kinetic plot of the reaction for $\mathrm{FeTMPyPCl}_{5}\left(25^{\circ} \mathrm{C}\right)$. The concentrations of the reagents were the same as in Fig. 6 except for $\mathrm{FeTMPyPCl}_{5}$ and $[t-\mathrm{BuOOH}]=2.89 \times 10^{-5} \mathrm{~mol}$ $\mathrm{dm}^{-3}$. 


$$
\begin{aligned}
(\mathrm{d}[\mathrm{Dye}] / \mathrm{d} t)_{0}=k_{\mathrm{obs}}[ & {[\mathrm{FeTMPyPCl}]_{0} } \\
& \times[\mathrm{DMA}]_{0}[t-\mathrm{BuOOH}]_{0} .
\end{aligned}
$$

$k_{\text {obs }}$ was estimated to be $7.5_{1} \times 10^{4} \mathrm{~mol}^{-2} \mathrm{dm}^{6} \mathrm{~s}^{-1}$.

\section{Mechanism of the reaction at $\mathrm{pH} 4.4$}

Under the present anaerobic conditions, even when hydroperoxide was added to the hemin solution without MBTH and DMA, no hemin-hydroperoxide adduct was observed and no degradation of hemin was indicated by the UV-vis spectra.

As mentioned before, two mechanisms for the cleavage of the $\mathrm{O}-\mathrm{O}$ bond of hydroperoxide coordinated on iron have been proposed. One was the heterolytic or ionic cleavage of the $\mathrm{O}-\mathrm{O}$ bond (Eq. (3)), resulting in the iron(V)-oxygen intermediate (1) and alcohol (2); the other was a homolytic or radical cleavage (Eq. (4)) resulting in the iron(IV) oxygen intermediate (3) and alkoxy radical (4). These mechanisms were proposed by different authors; ${ }^{23-30}$ others suggested that the cleavage depended on the conditions where it occurred. ${ }^{31}$

$$
\mathrm{ROOH}+\underset{\mid}{\mathrm{Fe}^{+}} \rightleftarrows\left[\underset{\mid}{\mathrm{FeOOR}} \underset{\mid}{\mathrm{H}} \underset{\mid}{\mathrm{FeOOR}}+\mathrm{H}^{+}\right]
$$

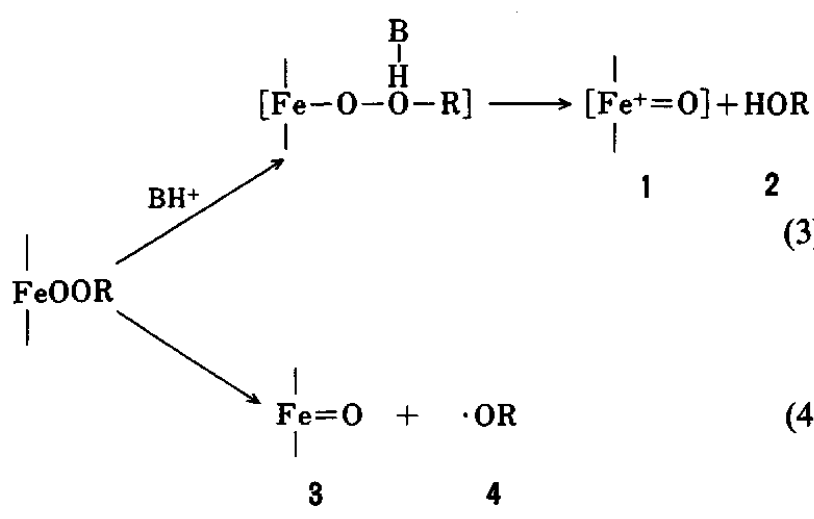

$\mathrm{Fe}^{+}$denotes FeTMPyP(X): under these conditions the fifth ligand $\mathrm{X}$ is $\mathrm{H}_{2} \mathrm{O}^{29,35}$, which is omitted in the equations for simplicity.

Because the reaction was not dependent on the concentration of MBTH, an actual dye formation took place after the step which formed an intermediate, "an activated oxygen" species, and which was rate-determining. The linear dependency on the DMA concentration indicated that DMA not only reacted to form the indamine dye, but also played the role of a general acidbase catalyst in the rate-determining step that cleaved the $\mathrm{O}-\mathrm{O}$ bond; DMA was protonated at the examined $\mathrm{pH}$ region $\left(\mathrm{p} K_{\mathrm{a}}=5.15^{32}\right)$. Supporting this, the addition of $N$ - $t$-butyl- $\alpha$-phenylnitrone (radical trapping reagent) to the reaction mixture did not affect the reaction (data not shown).

The reaction mechanism in the present case could thus explained as shown below. Hydroperoxide coordinated on iron(III) of hemin and heterolytic $\mathrm{O}-\mathrm{O}$ bond cleavage was followed to form active species:

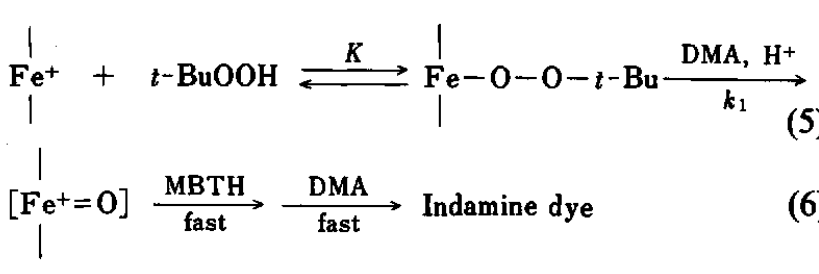

where $k_{\mathrm{obs}}=K \cdot k_{1}$.

The homolytic cleavage of the $\mathrm{O}-\mathrm{O}$ bond to form an alkoxy radical was thus excluded under the present reaction conditions. If an alkoxy radical is formed according to Eq. (4), the radical would react so as to result in a chain decomposition of hydroperoxide. This, however, was not the case.

The other interesting feature was that the reduction of hemin occurred in the $6-8 \mathrm{pH}$ region (data not shown). The reduction of hemin by MBTH was accelerated by adding $t$-BuOOH. This suggested that the different mechanism was dominant in the system which reduced hemin. ${ }^{33}$ The reduction of hemin and the formation of rearranged or decomposed compounds of $t$-BuOOH were reported regarding the Cytochrome P-450 system. ${ }^{34}$

Since the present determination of organic hydroperoxide was performed in the $4-5 \mathrm{pH}$ region, the existing enzymes, if any, in the sample solution would be less active. In the proposed assay method the handling of samples was direct and easy resulting in good reproducibility. Although hydrogen peroxide caused color formation, it could be determined separately at pH $1-2$, as previously described. ${ }^{14}$ Because the catalyzed reaction by water-soluble iron porphyrin was less specific to the kinds of peroxides, this method would be useful for fatty acid peroxide in cases in which actual enzyme systems, such as HRP or hemoglobin, might cause a problem regarding the specificity. This method would be arranged for an automatic assay in the field of clinical chemistry. Application of this method to the determination of lipid peroxide in biochemical systems is underway.

\section{References}

1. M. E. Bégin, Proc. Nutr. Soc., 49, 261 (1990).

2. D. Harman in "Free Radicals in Biology", ed. W. A. Pryor, Vol. V, pp. 255 - 275, Academic Press, New York, 1982.

3. C. Hackett, M. Linley-Adams, B. Lloyd and V. Walker, Clin. Chem., 34, 208 (1988).

4. B. Halliwell and M. Grootveld, FEBS Lett., 213, 9 (1987).

5. H. I. Kohn and M. Liversedge, J. Pharmacol. Exp. Therap., 82, 292 (1944).

6. K. Yagi, Biochem. Med., 15, 212 (1976).

7. H. Ohkawa, N. Ohishi and K. Yagi, J. Lipid Res., 19, 1053 (1978).

8. T. Asakawa, S. Matsushita, Lipids, 14, 401 (1979); ibid., 15, 137 (1980).

9. N. Ohishi, H. Ohkawa, A. Miike, T. Tatano and K. Yagi, 
Biochem. Int., 10, 205 (1985).

10. P. Görög, D. C. Kotak and I. B. Kovacs, J. Clin. Pathol., 44, 765 (1991).

11. Z-Y. Jiang, J. V. Hunt and S. P. Wolff, Anal. Biochem., 202, 384 (1992).

12. P. J. Marshall, M. A. Warso and W. E. M. Lands, Anal. Biochem., 145, 192 (1985).

13. H. W. S. Chan and F. A. A. Prescott, Biochem. Biophys. Acta, 380, 141 (1975).

14. T. Nakano and A. Takahashi, Anal. Sci., 6, 823 (1990).

15. T. T. Ngo and H. M. Lenhoff, Anal. Biochem., 105, 389 (1980).

16. M. F. Laker, A. F. Hofmann and B. J. D. Meeuse, Clin. Chem., 26, 827 (1980).

17. T. Segawa, A. Kakizaki, T. Kamidate and H. Watanabe, Anal. Sci., 8, 785 (1992).

18. N. Gochman and J. M. Schmitz, Clin. Chem., 18, 943 (1972).

19. P. J. Thornally, R. J. Trotta and A. Stern, Biochem. Biophys. Acta, 759, 16 (1983).

20. H. Kobayashi, T. Higuchi. Y. Kaizu, H. Osada and M. Aoki, Bull. Chem. Soc. Jpn., 48, 3137 (1975).

21. R. D. Mair and A. J. Graupner, Anal. Chem., 36, 194 (1964).

22. E. Sawicki, T. W. Stanley, T. R. Hauser, W. Elbert and J. L. Noe, Anal. Chem., 33, 722 (1961).

23. T. G. Traylor and J. P. Ciccone, J. Am. Chem. Soc., 111, 8413 (1989).

24. T. G. Traylor and F. Xu, J. Am. Chem. Soc., 112, 178
(1990).

25. T. G. Traylor, Pure Appl. Chem., 63, 265 (1991).

26. T. G. Traylor and F. Xu, J. Am. Chem. Soc., 109, 6201 (1987).

27. K. Murata, R. Panicucci, E. Gopinath and T. C. Bruice, J. Am. Chem. Soc., 112, 6072 (1990).

28. D. Mansuy, J.-F. Bartoli and M. Momenteau, Tetrahedron Lett., 23, 2781 (1982).

29. J. R. L. Smith and R. J. Lower, J. Chem. Soc. Perkin Trans., 1991, 31.

30. P. N. Balasubramanian, J. R. L. Smith, M. J. Davies, T. W. Kaaret and T. C. Bruice, J. Am. Chem. Soc., 111, 1477 (1989).

31. R. Labeque and L. J. Marnett, J. Am. Chem. Soc., 111, 6621 (1989).

32. "Dissociation Constants of Organic Acids in Aqueous Solution", ed. G. Kortün, W. Vogel and K. Andrussov, Butterworths, London, 1961.

33. T. Nakano and S. Miyata, Proceedings of the $63 \mathrm{rd}$ Annual Meeting of The Chemical Society of Japan, Osaka, March, 1992, p. 2081.

34. M. J. Coon, X. Ding, S. J. Pernecky and A. D. N. Vaz, FASEB J., 6, 669 (1992).

35. R. F. Pasternack, H. Lee, P. Malek and C. Spencer, $J$. Inorg. Nucl. Chem., 39, 1865 (1977).

(Received February 15, 1993)

(Accepted April 27, 1993) 